\title{
11 From mobility to complexity in sociolinguistic theory and method
}

\section{Jan Blommaert}

\section{Introduction}

In a celebrated article, Aaron Cicourel emphasized that "it is important to locate the analysis of language and social interaction in a wide variety of social activities that are implicitly and explicitly known to the participants and the investigator" (1992: 296). The case built in that article revolved around the challenge, notably in conversation analysis and other branches of discourse analysis, to do justice to the tremendous complexity characterizing real social environments - a medical environment in Cicourel's concrete study - and the need, consequently, to employ "several types of ethnographic and textual materials in order to underscore ... unavoidable aspects of organizational and local constraints and processes that are integral to rethinking "context"" (p. 309). If we accept, like Cicourel, that any form of human communication is set in a real social environment and draws on real and actual bodies of knowledge and experience of participants operating as "context" in social encounters, then tracing the sources of knowledge and experience of participants becomes a key issue, because "[a]s long as we continue to reify terms like 'social structure', 'culture' and 'language', we shall miss the contextual and cognitive significance of everyday social organization" (Cicourel 1973: 9) and we shall continue to impute our own, researchers', assumptions and biases to the people we study.

Such reifications, of course, are a legacy of structuralism and found their way into the standard methodologies of a good deal of contemporary social and human sciences. In sociolinguistics, Glyn Williams's (1992) critique of work as widely diverse as Labovian variationism, Fishmanian sociology of language, and Schegloffian conversation analysis demonstrated the lasting and pervasive influence of structural-functionalist consensus models handed down from Talcott Parsons (drawing in turn heavily on Durkheim). Such models, Williams explained, would imagine any social environment as an integrated 'complete' system displaying an elementary form of equilibrium, in which every individual member would know what was expected from him or her, and in which such knowledge would be accessible to all members. Thus, in 
mainstream sociolinguistics, "[t]he general discourse is ... the normative consensus view of society"; as for the speaker, he or she is imagined as a "free, rational individual capable of employing language not only to express meaning, but to convey a social identity"; groups tend "to be seen as the aggregate of individual rational behavior" (1992: 230-232); ${ }^{1}$ and as for society,

[t]he society within which the free, rational subject exists is a very specific form of society. It is an open society full of opportunity of which the rational and enterprising individual actor, operating on the basis of an inherent desire for social status, will be able to take full advantage. (p. 232)

Williams observes "that this model of society is very close to the North American world view, and to the individual liberalism which it encapsulates" (p. 234). It also stresses, and presupposes, clear, distinct, and stable social units that can become sociolinguistic units: the speech community, the dialect or language area, and language (or dialect, sociolect, etc.) itself (cf. Rampton 1998). Those are, evidently, the reifications that Cicourel saw as fundamental flaws in social and humanities research.

Recent decades have witnessed growing numbers of sociolinguists interrogating and unthinking these reifications. In the words of Blommaert and Rampton (2011: 3),

there has been ongoing revision of fundamental ideas (a) about languages, (b) about language groups and speakers, and (c) about communication. Rather than working with homogeneity, stability and boundedness as the starting assumptions, mobility, mixing, political dynamics and historical embedding are now central concerns in the study of languages, language groups and communication.

Unsurprisingly, these efforts often have their roots in the field, broadly taken, of multilingualism - one of sociolinguistics' core areas - and introductory textbooks on multilingualism now definitely look different from those published a couple of decades ago, to the extent that one might speak of a "postFishmanian" paradigm shift (e.g., Blackledge and Creese 2010; Weber and Horner 2012; see also Pennycook, this volume, (Chapter 9).

In this paradigm shift, new fundamental theoretical developments have been absorbed and incorporated into the analytical framework. An important one is the development of language ideologies as a field of macro- and microsociolinguistic research (e.g., Kroskrity 2000), now enabling a far more sophisticated view of "the contextual and cognitive significance of everyday social organization" emphasized above by Cicourel. We can now see how

${ }^{1}$ One of the most perfect examples of these views applied to sociolinguistics is Carol MyersScotton's well-known "Markedness Model" for code-switching. See Myers-Scotton (1992); an early but extensive critique of this model can be found in Blommaert and Meeuwis (1994). 
institutionalized interlanguage relationships and forms of sociolinguistic stratification are driven by particular ideological imaginings of language, culture, identity, and political structure (e.g., Blommaert 1999; Gal and Woolard 2001; Makoni and Pennycook 2006; see also Part I of this volume, Chapters 2-5), how languages and language varieties themselves can be analyzed as ideological constructs having a strong bearing on everyday language behavior, providing behavioral and discursive templates in language usage (e.g., Silverstein and Urban 1996; Agha 2007; Seargeant 2009). These developments have refocused sociolinguistic analysis, from reified notions of language (and dialect, sociolect, etc.) to a new kind of unit: an ideologically configured and indexically ordered set of specific linguistic-semiotic resources, sometimes coincident with what is commonly accepted as a language (e.g., English), but most often coincident with more specific notions such as "register", dynamically developing as "repertoires" in the course of people's social lives, and deployed in highly context-sensitive metalinguistically regimented social practices (e.g., Silverstein 2003 and this volume, Chapter 2; Rampton 2006; Agha 2007; Coupland 2007; Rymes 2014).

I have deliberately given some space to the importance of language ideologies as a keystone for what I qualified as the "post-Fishmanian" paradigmatic shift, because their impact is quite often oyerlooked or downplayed. But it is due to this development that we can now investigate sociolinguistic phenomena and processes that are defined in terms of fundamentally different units - flexible, unstable, dynamic, layered, and mobile ones. If studies of multilingualism now look quite different from those of a generation ago, it is to a large extent because researchers now can draw on a far more analytically precise vocabulary derived from language ideologies research. It is by means of this vocabulary that we can tackle the challenges earlier defined by Cicourel and Williams: to get rid of the reifying legacy of structuralism and to do justice to the complexity of sociolinguistic phenomena and processes.

In what follows, I shall outline these challenges and their paradigmatic potential for sociolinguistic theory and method at some length. I will sketch two steps: first, a move from stability to mobility - a move that is now largely accomplished; and second: from mobility to complexity - a move still very much in its initial stages. ${ }^{2}$ My discussion of the first move will be retrospective, as a consequence, while the second move can be discussed only programmatically. It will be followed by some remarks on the development of new methods for sociolinguistic research, after which I shall conclude with more general reflections.

${ }^{2}$ An earlier version of the following two sections can be found in Blommaert (2013: 6-14). 


\section{From stability to mobility}

As mentioned earlier, the paradigmatic shift has been most noticeable in the field of multilingualism, and the reason for that is straightforward: Multilingualism is a feature of sociocultural diversity, often associated with migration and sensitive to influences at both macro- and micro-levels, leading to highly complex, "messy," and hybrid sociolinguistic phenomena that defy established categories. To start with the macro-levels: Migration as a force behind multilingualism compels analysts to consider mobile people - people who do not stay in the place where their languages are traditionally used, to put it simply whose linguistic resources and communicative opportunities are affected by such forms of mobility. New forms of migration due to post-Cold War globalization processes combined with the emergence of online technologies as current features of social life - what Steven Vertovec called "superdiversity" (2007) - have generated complex social-communicative environments and webs of mobile people, semiotic modes and forms, and meanings.

The study of these environments called for a sociolinguistics of globalization, and the central notion in early attempts in that direction was mobility (Coupland 2003; 2010; Pennycook 2007; Blommaert 2010). In itself, this move represents a major theoretical effort, for it disrupts the long tradition, reviewed by Glyn Williams, in which language, along with other social and cultural features of people, was primarily imagined as relatively fixed in time and space, as sedentary, so to speak. A language or language variety was something that "belonged" to a definable (and thus bounded) "speech community"; that speech community lived in one place at one time and, consequently, shared an immense amount of contextual knowledge. That is why people understood each other: They knew all the social and cultural diacritics valid in a stable sociolinguistic community and could, thus, infer such contextual knowledge in interactions with fellow members of that community. Roles and expectations were clear and well understood in such contexts - children had respect for elder people and so forth. And people reproduced patterns that were seen as anchored in a timeless tradition - the rules of language usage are what they are, because the rules of society are what they are (for a critique, see Rampton 1998). Social and linguistic features were members of separate categories between which stable and linear correlations could be established.

From the very early days of sociolinguistics, however, alternative views were available. John Gumperz and Dell Hymes (1972), for instance, quickly destabilized these assumptions in their programmatic work on ethnographies of communication, and they did so with one apparently simple theoretical intervention: They defined social and linguistic features not as separate-butconnected but as dialectic, that is, co-constructive and, hence, dynamic. Concretely: The reiteration of specific patterns of language usage - say, the use of 
"yes sir" as an answer in a hierarchical speech situation - creates a social structure (hierarchy) which in turn begins to exert a compelling effect on subsequent similar speech situations. It has become a 'rule' or a 'norm' and so becomes an ideologically saturated behavioral expectation and an aim for effect in communication. But such 'rules' or 'norms' have no abstract existence; they have an existence only in iterative communicative enactment. People need to perform such ideologically saturated forms of behavior - their behavior must be iterative in that sense - but small deviations from that rule have the capacity to overrule the whole of norm-governed behavior. Saying "yes sir" with a slow and dragging intonation, for instance ("yeeees siiiiiiiir"), can express irony and so entirely cancel the norm, and even become the onset of an alternative norm.

The importance of this simple but fundamental change in perspective is massive, even if it took a while before it was fully taken on board, for it introduced a dimension of contingency and complexity into sociolinguistics that defied the static correlational orthodoxies. Deviations from norms, for instance, can now be the effect of a whole range of factors, and it is impossible to make an a priori choice for any of them. The dragging intonation in our example above can be the result of intentional subversiveness, but it can also be the effect of degrees of 'membership' in speech communities - whether or not one 'fully' knows the rules of the sociolinguistic game. So, simple correlations do not work anymore; they need to be established by means of ethnographic examination (Hymes 1996: 31-32). Such examination, while always more complicated than anticipated, was easier in communities that displayed a relative sociocultural homogeneity, and a significant part of research in the ethnography of communication focused on group-internal ways and rules of speaking (e.g., Schieffelin 1990). Investigating more "mixed" contexts, such as interethnic communication in British professional contexts (e.g., Gumperz 1982) or ethnically heterogeneous inner-city schools in urban Britain (Rampton 1995), made clear that when people move around the globe, their communicative resources are affected by such moves: Accents, styles, modes of conversational arrangement all proved to be sensitive to mobility, and what worked well in one part of the world proved to lose functional efficacy in another. Reasons for such differences are rarely "linguistic" in the strict sense of the term: They are indexical (cf. Part I of this volume, Chapters 2-5). It is the language-ideological framing-in-uptake of accents, styles, and so on that changes whenever people move from one place to another, and the complex processes of (re-)contextualization central to John Gumperz's work are in fact indexical in nature (a point acknowledged in his later work; see Gumperz 2003: 110-113). Mobility, sociolinguistically, is therefore a matter of determining the different orders of indexicality through which communication travels, and their effect on communicative conditions and outcomes (Blommaert 2010: 41-43; also Jacquemet 2005). 
Taking mobility as the central concept in a sociolinguistics of globalization has, in my view, three major methodological effects: (1) it creates a degree of unpredictability in what we observe, and we can solve this unpredictability only (2) by close ethnographic inspection of the minutiae of what happens in communication and (3) by keeping in mind the intrinsic limitations of our current methodological and theoretical vocabulary - thus, by accepting the need for new images, metaphors, and notions to cover adequately what we observe. The challenge of mobility is paradigmatic, not superficial (cf. also Rampton 2006; Jaworski and Thurlow 2010; Pennycook 2010; 2012).

The paradigmatic nature of the challenge is hard to escape when one addresses the many forms of multilingual communicative behavior that appear to characterize the present world and for which scholars have developed terms such as 'languaging', 'polylanguaging', 'crossing', 'metrolingualism', 'transidomatic practices', and so forth (Blommaert and Rampton 2011 provide a survey; see also Pennycook, this volume, Chapter 9). In superdiverse environments (both on- and offline), people appear to take any linguistic and communicative resource available to them - a broad range, typically, in superdiverse contexts - and blend them into hugely complex linguistic and semiotic forms. Old and established terms, such as 'code-switching' and indeed even 'multilingualism', appear to rapidly exhaust the limits of their descriptive and explanatory adequacy in the face of such highly complex 'blends' (cf. Creese and Blackledge 2010; Sharma and Rampton 2011; Backus 2012).

And not only that: Two additional issues emerge. First, the question of the origin and trajectory of the actual resources that constitute the blend, how they have been acquired, and what kind of 'competence' they would represent is equally difficult to answer. Contemporary repertoires are tremendously complex, dynamic, and unstable and not predicated on the forms of knowledge-oflanguage one customarily assumes, since Chomsky, with ordinary language users. Important issues of what it means to "know" and "use" a language emerge here (e.g., Rampton 1995; Moore 2012; Blommaert and Backus 2013; Rymes 2014; Zentz 2015). Profoundly sociolinguistic issues such as the specific communicative resources deployable and deployed in discourse and differential fluency in and command over such resources between participants in communication were central to the research programs of Gumperz (e.g., 1982) and Hymes (e.g., 1996); in the context of globalization, they are back with a vengeance, as work on, for example,e.g., asylum seekers in the West mobile people par excellence - has shockingly demonstrated (e.g., Maryns 2006; see Eades 2010 for an overview).

Second, the sociolinguistic environments in which such forms circulate and are being deployed also demand further attention. While many of the "messy" forms of language use currently analyzed as aspects of sociolinguistic superdiversity may have precedents in earlier eras, they now operate in a 
sociolinguistic environment which, certainly due to the massive presence of online and long-distance communicative contexts, contains features not previously attested. In other words, while superdiversity may not have brought many really "new" linguistic phenomena, the new sociolinguistic aspects cannot be avoided. There are new and extraordinarily large online (i.e. "transidiomatic", in the sense of Jacquemet 2005) communities developing specialized modes of communication on their platforms involving new identity performance opportunities as well as new norms for appropriate communicative behavior and requiring new kinds of visual literacy-based semiotic work in new genres and registers (e.g., Androutsopoulos 2006; Varis and Wang 2011). These new online and long-distance contexts challenge established understandings of core features of "natural" communication (such as physical co-presence, sharedness of medium and communicative resources, and oral performance as the elementary form of language) and invite new forms of research - if for nothing else, because of the ways in which online contexts affect more conventional "offline" communicative environments. There is now a genuinely global contextual scale level, which combines space-time scope with speed and volume in ways previously unthinkable, creating a poorly understood new level of globalized mobility. ${ }^{3}$ Consequently, the sociolinguistic economies of contemporary societies - the entire range of resources circulating in societies, their distribution, and their mutual relationships - need to be investigated anew, and pending that it is safe to assume that these economies display important differences with those of preceding generations.

Let me summarize the argument so far. Globalization as a sociolinguistic phenomenon has made scholars increasingly aware of the deficiencies of earlier theoretical models and analytical frameworks, based on imageries of stable, resident and sedentary speech communities in an integrated society; it has compelled them to see sociolinguistic phenomena and processes as objects fundamentally characterized by mobility. Taking mobility as a paradigmatic principle of sociolinguistic research dislodges several major assumptions of mainstream sociolinguistics and invites a more complex, dynamic, and multifaceted view of sociolinguistic realities. As announced above, I consider this move to be largely accomplished, even if much important work remains to be done. Such work, however, can benefit from an additional move: from mobility to complexity.

\section{From mobility to complexity}

The point of departure for this second move is the need to reimagine the sociolinguistic phenomena and processes we intend to study, now detached

${ }^{3}$ To judge these developments from within a broader historical perspective, Burke (2011) is commendable. 
from the older imagery discussed and dismissed above. To reimagine can be taken literally here: What is needed is a set of images and metaphors that appear to offer more and better analytical opportunities because they correspond better to the phenomena and processes we observe. I would suggest that chaos (or complexity) theory offers us such images and metaphors, and I will allow myself to be inspired in this direction by two early works: Conrad Waddington's (1977) Tools for Thought about complex systems and Ilya Prigogine and Isabelle Stengers's (1984) classic Order out of Chaos. Note, and I emphasize this, that what follows is not an attempt to bring Chaos Theory (with capitals) into sociolinguistics; it is merely an attempt at drawing inspiring images and metaphors from those sources into sociolinguistics. As said, this second move can only be programmatic, and adequate images and metaphors help us construct a deep level of theorizing. We can use complexity as a perspective, not as a compulsory vocabulary or theoretical template. It offers a freedom to imagine, not an obligation to submit.

The two books, when they appeared, introduced a universe of complex systems: systems that are open and unfinished, in and on which several apparently unrelated forces operate simultaneously but without being centrally controlled or planned, so to speak. In such systems, change is endemic and perpetual, because of two different dynamics: interaction with other systems (an external factor), and intrasystem dynamics and change affected by such exchanges with others but also operating autonomously (an internal factor). Consequently, no two interactions between systems are identical, because the different systems would have changed by the time they entered into the next ('identical') interaction. Repeating a process never makes it identical to the first one, since repetition itself is a factor of change. The authors also stressed the importance of contingency and accident - the 'stochastic' side of nature. General patterns can be disrupted by infinitely small deviations - things that would belong to statistical 'error margins' can be more crucial in understanding change than large 'average' patterns. And they emphasized the non-unified character of almost any system, the fact that any system can and does contain forces and counterforces, dominant forces and 'rebellious' ones.

Particularly inspiring, of course, is the insight that chaos is not an absence of order but a specific form of order, characterized, intriguingly, by the increased interaction, interdependence, and hence coherence between different parts of a system. And the assumption that such general chaotic patterns can be found at every scale level - authors usually distinguish the microscopic world from the macroscopic one - is both challenging and productive as well. Finally, but more speculatively, the notion of entropy can be useful to keep in mind: Systems inevitably develop entropy, a loss of the energy that characterizes their nonequilibrium state, and tend to develop towards uniformity. Their 
internal pattern of change, in other words, tends towards homogeneity and the reduction of the intense energy of diversity.

Those ideas are decades old by now, and many of them have become common sense. But not, I observe with regret, in sociolinguistics and many other branches of the human and social sciences, nor in public policy. They have more influence and are much better understood in New Age movements than in the EU Commission or in any university department of sociolinguistics, and this is a pity. ${ }^{4}$ When we apply them to sociolinguistics, we arrive at an entirely new range of baseline images for "complex sociolinguistics", which I can summarize in a set of theoretical propositions.

1. A sociolinguistic system is a complex system characterized by internal and external forces of perpetual change, operating simultaneously and in unpredictable mutual relationships. It is therefore always dynamic, never finished, never bounded, and never completely and definitively describable, either. By the time we have finished our description, the system will have changed. As for the notion of 'sociolinguistic system', it simply stands for any set of systemic regular, recurrent, nonrandom - interactions between sociolinguistic objects at any level of social structure.

2. Sociolinguistic systems are not unified, either. In earlier work, I used the notion of 'polycentricity' to identify the fragmentation and the interactions between fragments of a sociolinguistic system (Blommaert 2010: 32-41). A sociolinguistic system is always a 'system of systems', characterized by different scale levels - the individual is a system, his or her peer group is one, his or her age category another, and so on; we move from the smallest 'microscopic' or 'nanosociolinguistic' level (Parkin 2012: 74) to the highest 'macroscopic' scale level. Centers in a polycentric system typically occupy specific scale levels and operate as foci of normativity, that is, of ordered indexicalities (Silverstein 2003; Blommaert 2005; Agha 2007). The norms valid in a small peer group are different from those operating on the same individuals in a school context, for instance.

3. Going back to what was established earlier: Sociolinguistic systems are characterized by mobility; in the constant interaction within and between systems, elements move across centers and scale levels. In such forms of mobility, the characteristics of the elements change: Language varieties that have a high yalue here can lose that value easily by moving into another 'field of force', so to speak - another sociolinguistic system. Concretely, an accent in English that bears middle-class prestige in Nairobi can be turned into a stigmatized immigrant accent in London.

\footnotetext{
${ }^{4}$ I am being unfair here towards the very interesting attempts made by some people in our field to adapt complexity/chaos theory to linguistic and sociolinguistic phenomena; see, e.g.,, Diane Larsen-Freeman's work on language learning (Larsen-Freeman 1997).
} 
4. The reason for such changes is historical: The value and function of particular aspects of a sociolinguistic system are the outcome of historical and local processes of becoming. At the lowest level of language, word meanings are 'conventional', that is, 'historically entrenched as meaning x or y'; historicity creates recognizability, grounded in indexical attributions: I hear $\mathrm{x}$, and I recognize it as conventionally and indexically meaning $\mathrm{y}$. This also counts for higher-order levels such as genres, styles, discourse traditions, and other forms of intertextuality and interdiscursivity.

5. In a complex system, we will encounter different historicities and different speeds of change in interaction with each other, collapsing in synchronic moments of occurrence. Long histories - the kind of history that shaped 'English', for instance - are blended with shorter histories - such as the one that produced hip-hop jargon, for instance. I called this layered simultaneity' in earlier work (2005: 126): In communication, resources are used that have fundamentally different historicities and therefore fundamentally different indexical loads. The process of lumping them together, and so eliding the different historicities inscribed in them, I called "synchronization". Every synchronic act of communication is a moment in which we "synchronize" materials, each of which carries very different historical indexicalities, an effect of the intrinsic polycentricity that characterizes sociolinguistic systems.

6. The previous statement, when initially formulated, was a general typification of discourse, from individual utterance to text and discourse complex. We can make the same statement with respect to larger units as well, as a typification of entire zones of communication and of communicative systems in general, because of 'fractal recursivity': the fact that phenomena occurring on one scale level also resonate at different scale levels (Irvine and Gal 2000). The intrinsic hybridity of utterances (something, of course, introduced by Bakhtin a long time ago) is an effect of interactions within a much larger polycentric system.

7. The "synchronization" mentioned earlier is an act of interpretation in which the different historical layers of meaning are folded into one 'synchronic' set of meanings. This is a reduction of complexity, and every form of interpretation can thus be seen as grounded in a reduction of the complex layers of meaning contained in utterances and events - a form of entropy, in a sense. People appear to have a very strong tendency to avoid or reduce complexity, and popular 'monoglot' language ideologies (Silverstein 1996), as well as 'homogeneistic' language and culture policies, can exemplify this tendency. While the default tendencies of the system are towards entropy - uniformity, standardization, homogenization - the perpetual 'chaotic' dynamics of the system prevent this finite state. In sociolinguistic systems, we are likely to always encounter tensions between tendencies 
towards uniformity and tendencies towards heterogeneity. In fact, this tension may characterize much of contemporary social and cultural life (see Blommaert and Varis 2012).

8. In line with the previous remarks, change at one level also has effects at other levels. Every instance of change is at least potentially systemic, since changes in one segment of the system have repercussions on other segments of that system. Every "micro" occurrence, therefore, can also be read as a "macro" feature. A simple example is the way in which parents can be influenced by their teenage children's Internet gaming jargon and effectively adopt it in their own speech, even when these parents themselves have never performed any online gaming in their lives. A change in one segment (the teenagers) affects other segments (their parents) and is provoked by higherscale features (the often global jargon of online gaming communities). Similarly, as noted earlier, the introduction and spread of the Internet and other mobile long-distance communication instruments has changed the entire sociolinguistic economy of societies; the change, thus, affects not just those who intensively use such technologies, but also those who lack access to them.

9. The latter remark has a methodological consequence. The loci of macroscopic change can be microscopic and unpredictable; large-scale change can be triggered by individual contingencies or recurrences of seemingly insignificant deviations - the stochastic side of sociolinguistic systems. A jurisprudencedriven legal system is a good illustration (cf. Eades, this volume, Chapter 17): A single highly contingent ruling by a judge can change the whole system of legislation on related issues. This means that microscopic and detailed investigation of cases - ethnography, in other words - is perhaps the most immediately useful methodology for investigating systemic sociolinguistic aspects (cf. Rampton 2006; Blommaert and Rampton 2011). The precise direction of change is unpredictable as well because of the unpredictability of the other factors. We know that systems change irreversibly - we know, thus, that there is a vector of change - but what exactly the outcome of change will be is hard to determine. We can believe in a certain direction of change, but we will not necessarily see it happen. The history of language planning across the globe is replete with unexpected (and often unwelcome and unhappy) outcomes.

10. In view of all this, the task of analysis is not to reduce complexity - to reiterate, in other words, the synchronization of everyday understanding - but to demonstrate complexity, to unfold the complex and multifiliar features and their various different origins that are contained in synchronized moments of understanding. The recognition that the synchrony of linguistics and sociolinguistics (the so-called Saussurean synchrony) is in actual fact an ideologically plied habit of synchronization evidently destroys that synchrony (cf. Blommaert 2013: 117-119). 
I realize that all of these points sound rather abstract and perhaps daunting; I can reassure my readers, however, that these points merely summarize and reformulate insights repeatedly established in sociolinguistic and linguisticanthropological literature by now; they represent the second move of the paradigm shift, which merely extends and broadens the acquired insights of the first move. The terms in which I have couched my points are there because they enable us to imagine the sociolinguistics of superdiversity as organized on an entirely different footing from that which characterized the Fishmanian, Labovian, and Schegloffian sociolinguistic world. In fact, several of the points flatly contradict some of the most common assumptions in the study of language in society - the boundedness of speech communities; the stability, linearity, and even predictable nature of sociolinguistic variation; the linear nature of linguistic and sociolinguistic evolution; the autonomy and boundedness of language itself; the assumption of sharedness of resources among speakers; and so forth - the structuralist reifications identified by the likes of Cicourel and Williams. They have now been replaced by a baseline imagery of openness, dynamics, multifiliar and nonlinear development, unpredictability. What used to be considered deviant and abnormal - complexity, hybridity, and other forms of 'impurity' in language use - has become, in this perspective, normal.

\section{Towards method}

Recall Cicourel's insistence, quoted at the outset, on the need to employ "several types of ethnographic and textual materials in order to underscore ... unavoidable aspects of organizational and local constraints and processes that are integral to rethinking "context"' (Cicourel 1992: 309). We need an aggregate of methods that reflects the complexity of the cases we investigate, and methods that do not simplify these cases to a one-dimensional skeleton structure. I have repeatedly gestured towards ethnography as a privileged set of instruments for studying complexity, but that in itself is not sufficient and the issue is not all that simple. Let me briefly review some important aspects of the task of designing methods for a complex sociolinguistics.

1. The biggest challenge in research is how to avoid statifying and stabilizing what is, in effect, a dynamic and unstable given. In other words, we need methods that enable us to focus on change itself, on how and why sociolinguistic environments do not stay the same over time and in different conditions. The points that follow sketch aspects of this issue.

2. As outlined earlier, events always emerge under the influence of different (and often unclearly related) forces. Given this non-unified nature of sociolinguistic events and of speech deployed in them, simple notions of "context" will not do. It is good to return to Cicourel's (1992) remarks here, directed, as we 
know, against the deeply flawed notion of context, interpreted as directly inferenceable (and explicitly enacted) sociocognitive information; this was the interpretation that Cicourel had detected in Schegloffian conversation analysis. Cicourel's argument was that, in order to just describe what participants in the medical encounters he had studied actually do in the way of meaning-making, it was vital to identify several very different bodies of "contextual" material influencing their actions - most of it invisible in the interaction itself but definitely present as assumptions, identity categories, action templates, and frames for understanding in the encounters. It was possible, drawing on this richer set of "contextual" levels, to see such medical encounters not as just one (sequentially developing) activity but as an agglomerate of different sequential and interlocking activities, "nested" in other activities and involving small and delicate, but interpretively substantial, genre and footing shifts, some oriented to the interaction here-and-now, others pointing to different (present or absent) participants or anticipating subsequent steps in the activity. As for the latter, medical encounters typically also lead to post hoc case discussions by the medical team, to iterative uptake in later encounters with other patients, to archived case files, reports, and publications, and so forth - and all of these play a role in the single and uniquely situated ("micro") encounter itself, which thereby acquires a systemic ("macro") dimension. ${ }^{5}$ Such encounters, thus, constituted not just one context (that of the encounter itself) but several related yet very different "contexts" (cf. also Briggs 1997). The encounter was polycentric, we would now say.

It is an elementary step in the development of method, I believe, to assume that every case of actual social interaction we study is couched in layers upon layers of relevant contexts and that awareness of the salience of different context levels is not sidelined whenever we focus on specific ones. Every momentary context is shaped by conditions created earlier and has the potential to shape ulterior conditions as well, and any adequate "contextual" sociolinguistic analysis must identify these "transcontextual" influences.

3. This point has a bearing on the ways in which we currently use standard "data" artifacts, such as transcribed recordings. Transcripts have a tendency to suggest one single sequentially organized activity in which every turn can be read as responding to a previous one hearable in the audio-recording - while in fact, it was an activity in its own right or responded to an entirely different prompt signaling a different participation framework. The uniformity of activity (and thus of context, as we saw) can never be taken for granted. Neither can the nature of activity be taken for granted: We very often take transcripts to

5 Cicourel's The Social Organization of Juvenile Justice (1968) developed this issue in spectacular detail and remains, therefore, a methodological classic. See also the discussion of "forgotten contexts" in Blommaert (2005: 56-66). 
represent a "conversation", whereas closer inspection reveals frequent genre and register shifts within a conversation, with micro-narratives, shouts, or shifts from one-to-one to group-oriented speech - all being extraordinarily important to understand what goes on. The complexity of communicative events needs to be reflected in the data artifacts we employ to study them. To rephrase Cicourel, "textual materials" such as transcripts need to be complemented by "ethnographic materials" providing clues about how to use the transcript.

4. As for quantitative methods (now including "big data" mining techniques), the stochastic nature of sociolinguistic systems ought to sensitize us to the fact that statistical frequencies or averages might not be the key to understanding a sociolinguistic environment; the really relevant elements triggers of large-scale change, for instance - can be exceptional, deviant, and statistically insignificant. Really influential forces, as we know, may be characterized precisely by their infrequency of occurrence. Survey work needs to be driven by ethnographically established and ecologically valid questions and insights, and quantitative outcomes need to be ethnographically verified (Cicourel 1964; also Blommaert and van de Vijver 2013; for examples, see Sharma and Rampton 2011; Rampton 2012).

5. A set of methods needs to be designed for addressing the new sociolinguistic environments, mentioned earlier, that characterize superdiversity. Some work has been done already on online ethnography (e.g., Beaulieu 2004; Androutsopoulos 2008); but work on the interaction between online and offline sociolinguistic life very much awaits development (Varis 2014 provides a survey). As mentioned earlier, the presence of new communication and information technologies has reshuffled the sociolinguistic economies of contemporary societies, leading to new repertoires and forms of semiotic work characterized by visual literacy-driven resources and practices. This is disturbing for a science more at ease with (and privileging) spoken language usage as the baseline material for sociolinguistic inquiry and traditionally rather poorly equipped for addressing literate materials (Lillis 2013). New multimodal methods of analysis need to come into circulation in order to adequately tackle the various challenges posed by these new and very rapidly evolving sociolinguistic environments.

Accepting and foregrounding the complexity of sociolinguistic phenomena and processes evidently does not make life easier for sociolinguists; indeed, it renders the job of adequate analysis vastly more complex. We must realize that a paradigmatic shift such as the one outlined here will involve the disqualification, not so much of actual analytical techniques (we will forever be recording and transcribing talk), but of the assumptions we hold about them and about their results. Far more multifaceted forms of research will have to be constructed, combining (in demanding ways) advanced skills in a variety of 
methods and approaches, but held together and made coherent by a clearly established and defined research object. It is to be anticipated that the next decade will see a flurry of innovation in the field of sociolinguistic method; it will also undoubtedly see developments in research ethos and strategy, with more attention (and respect) for interdisciplinarity, "mixed methods" and teamwork. This, I believe, is to be welcomed.

\section{Conclusion}

Dell Hymes opened his essay "Models of the Interaction of Language and Social Life" with this simple sentence: "Diversity of speech has been singled out as the main focus of sociolinguistics" (Hymes 1972: 38). In defining the object of sociolinguistics in this way, he reacted against the hegemony of a science of language that focused on the static, the stable, the eternal, and the universal in language, and proposed a science that would explain the actual ways in which language operated in social life and played a role in structuring society. These ways were diverse, and that meant that they were not deducible from general rules of grammar or cognition, not stable over time nor unaffected by history and human agency.

I find this definition of the scope of sociolinguistics still the clearest and most convincing argument in favor of sociolinguistics, its unique raison d'être. But accepting it involves accepting diversity as change, both in the nature and structure of our object and in the approaches we develop for analyzing it. The fact that paradigmatic shifts, such as the ones outlined here, occur and even intensify is testimony of the usefulness of existing approaches: They took us to the point where we experienced their limits and the need to revise and improve them. We have in the past decades come to recognize language in society as a domain that has undergone deep and fundamental changes at all levels, as part of deep and fundamental changes of the world at large. The "creative destruction" (to use Schumpeter's well-worn term) involved in this recognition leads us to a more accurate and precise science, of greater relevance to other disciplines and more useful to the people and communities we observe and study.

\section{REFERENCES}

Agha, Asif. 2007. Language and Social Relations. Cambridge: Cambridge University Press.

Androutsopoulos, Jannis. 2006. Multilingualism, diaspora, and the Internet: Codes and identities on German-based diaspora websites. Journal of Sociolinguistics 10, 4: 520-547.

2008. Potentials and limitations of discourse-centred online ethnography. Language@Internet 5, article 9. www.languageatinternet.org/articles/2008/1610/ androutsopoulos.pdf. 
Backus, Ad. 2012. A usage-based approach to borrowability. Tilburg Papers in Culture Studies, paper 27.

Beaulieu, Anne. 2004. Mediating ethnography: Objectivity and the making of ethnographies of the internet. Social Epistemology 18: 139-163.

Blackledge, Adrian, and Angela Creese. 2010. Multilingualism: A Critical Perspective. London: Bloomsbury.

Blommaert, Jan. 2005. Discourse: A Critical Introduction. Cambridge: Cambridge University Press.

2010. The Sociolinguistics of Globalization. Cambridge: Cambridge University Press.

2013. Ethnography, Superdiversity and Linguistic Landscapes: Chronicles of Complexity. Bristol: Multilingual Matters.

(ed.). 1999. Language Ideological Debates. Berlin: Mouton de Gruyter.

Blommaert, Jan, and Ad Backus. 2013. Superdiverse repertoires and the individual. In Ingrid de Saint-Georges and Jean-Jacques Weber (eds.), Multilingualism and Multimodality: Current Challenges for Educational Studies. Rotterdam: Sense Publishers, 11-32.

Blommaert, Jan, and Michael Meeuwis. 1994. The Markedness Model and the absence of society: Remarks on codeswitching. Multilingua 13, 4: 397-423.

Blommaert, Jan, and Ben Rampton. 2011. Language and superdiversity. Diversities 13, 2: $1-22$.

Blommaert, Jan, and Fons van de Vijver. 2013. Combining surveys and ethnographies in the study of rapid social change. Working Papers on Urban Language and Literacies 108.

Blommaert, Jan, and Piia Varis. 2012. Culture as accent. Tilburg Papers in Culture Studies 18.

Briggs, Charles. 1997. Notes on a "confession": On the construction of gender, sexuality, and violence in an infanticide case. Pragmatics 7, 4: 519-546.

Burke, Peter. 2011. The Social History of Knowledge, vol. 2: From the Encyclopaedia to Wikipedia. Cambridge: Polity.

Cicourel, Aaron. 1964. Method and Measurement in Sociology. New York: Free Press. 1968 [2013]. The Social Organization of Juvenile Justice. New Brunswick, NJ: Transaction Publishers.

1973. Cognitive Sociology: Language and Meaning in Social Interaction. Harmondsworth: Penguin Education.

1992. The interpenetration of communicative contexts: Examples from medical encounters. In Alessandro Duranti and Charles Goodwin (eds.), Rethinking Context: Language as an Interactive Phenomenon. Cambridge: Cambridge University Press, 291-310.

Coupland, Nikolas. 2007. Style: Language Variation and Identity. Cambridge: Cambridge University Press.

(ed.). 2003. Journal of Sociolinguistics 7/4 (Thematic issue on Sociolinguistics and Globalisation).

(ed.). 2010. The Handbook of Language and Globalization. New York and London: Wiley Blackwell.

Creese, Angela, and Adrian Blackledge. 2010. Towards a sociolinguistics of superdiversity. Zeitschrift für Erziehungswissenschaften 13: 549-572. 
Eades, Diana. 2010. Sociolinguistics and the Legal Process. Bristol: Multilingual Matters.

Gal, Susan, and Kathryn Woolard (eds.). 2001. Languages and Publics: The Making of Authority. Manchester: St. Jerome.

Gumperz, John. 1982. Discourse Strategies. Cambridge: Cambridge University Press. 2003. Response essay. In Susan Eerdmans, Carlo Prevignano, and Paul Thibault (eds.), Language and Interaction: Discussions with John J. Gumperz. Amsterdam: John Benjamins, 105-126.

Gumperz, John, and Dell Hymes (eds.). 1972. Directions in Sociolinguistics: The Ethnography of Communication. New York: Holt, Rinehart and Winston.

Hymes, Dell. 1972 [1986]. Models of the interaction of language and social life. In John Gumperz and Dell Hymes (eds.), Directions in Sociolinguistics: The Ethnography of Communication. London: Basil Blackwell, 35-71.

1996. Ethnography, Linguistics, Narrative Inequality: Toward an Understanding of Voice. London: Taylor \& Francis.

Irvine, Judith, and Susan Gal. 2000. Language ideology and linguistic differentiation. In Paul Kroskrity (ed.), Regimes of Language. Santa Fe, NM: SAR Press, 35-83.

Jacquemet, Marco. 2005. Transidiomatic practices: Language and power in the age of globalization. Language and Communication 25, 3: 257-277.

Jaworski, Adam, and Crispin Thurlow. 2010. Language and the globalizing habitus of tourism: Towards a sociolinguistics of fleeting relationships. In Nikolas Coupland (ed.), The Handbook of Language and Globalization. Oxford: Wiley-Blackwell, 255-286.

Kroskrity, Paul (ed.). 2000. Regimes of Language. Santa Fe, NM: SAR Press.

Larsen-Freeman, Diane. 1997. Chaos/complexity science and second language acquisition. Applied Linguistics 18, 2: 141-165.

Lillis, Theresa. 2013. The Sociolinguistics of Writing. Edinburgh: Edinburgh University Press.

Makoni, Sinfree, and Alastair Pennycook (eds.). 2006. Disinventing and Reconstituting Languages. Bristol: Multilingual Matters.

Maryns, Katrijn. 2006. The Asylum Speaker: Language in the Belgian Asylum Procedure. Manchester: St. Jerome.

Moore, Robert M. 2012. "Taking up speech" in an endangered language: Bilingual discourse in a heritage language classroom. Working Papers in Educational Linguistics 27, 2: 57-78.

Myers-Scotton, Carol. 1992. Social Motivations for Codeswitching: Evidence from Africa. Oxford: Clarendon Press.

Parkin, David. 2012. From multilingual classification to translingual ontology: Concluding commentary. Diversities 14, 2: 71-85.

Pennycook, Alastair. 2007. Global Englishes and Transcultural Flows. London: Routledge.

2010. Language as a Local Practice. London: Routledge.

2012. Language and Mobility: Unexpected Places. Bristol: Multilingual Matters.

Prigogine, Ilya, and Isabelle Stengers. 1984. Order out of Chaos: Man's New Dialogue with Nature. New York: Bantam Books.

Rampton, Ben. 1995. Crossing: Language and Ethnicity among Adolescents. London: Longman. 
1998. Speech community. In Jef Verschueren, Jan-Ola Östman, Jan Blommaert, and Chris Bulcaen (eds.), Handbook of Pragmatics, 1998 Installment. Amsterdam and New York: John Benjamins, 1-30.

2006. Language in Late Modernity. Cambridge: Cambridge University Press.

2012. Drilling down to the grain in superdiversity. Working Papers in Urban Language and Literacies 98.

Rymes, Betsy. 2014. Communicating beyond Language: Everyday Encounters with Diversity. New York: Routledge.

Schieffelin, Bambi. 1990. The Give and Take of Everyday Life: Language Socialization of Kaluli Children. Cambridge: Cambridge University Press.

Seargeant, Philip. 2009. The Idea of English in Japan: Ideology and the Evolution of a Global Language. Bristol: Multilingual Matters.

Sharma, Devyani, and Ben Rampton. 2011. Lectal focusing in interaction: A new methodology for the study of superdiverse speech. Working Papers in Urban Language and Literacies 79.

Silverstein, Michael. 1996. Monoglot "Standard" in America: Standardization and metaphors of linguistic hegemony. In Donald Brenneis and Ronald Macaulay (eds.), The Matrix of Language. Boulder, CO: Westview Press, 284-306.

2003. Indexical order and the dialectics of sociolinguistic life. Language and Communication 23: 193-229.

Silverstein, Michael, and Greg Urban (eds.). 1996. Natural Histories of Discourse. Chicago, IL : University of Chicago Press.

Varis, Piia. 2014. Digital ethnography. Tilburg Papers in Culture Studies 103.

Varis, Piia, and Xuan Wang. 2011. Superdiversity on the internet: A case from China. Diversities 13, 2: 71-83.

Vertovec, Steven. 2007. Super-diversity and its implications. Ethnic and Racial Studies 30, 6: 1024-1054.

Waddington, Conrad H. 1977. Tools for Thought. St. Albans: Paladin.

Weber, Jean-Jacques, and Kristine Horner. 2012. Introducing Multilingualism: A Social Approach. London: Routledge.

Williams, Glyn. 1992. Sociolinguistics: A Sociological Critique. London: Routledge.

Zentz, Lauren. 2015. "Is English also the place where I belong?" Linguistic biographies and expanding communicative repertoires in Central Java. International Journal of Multilingualism 12, 1: 68-92. 


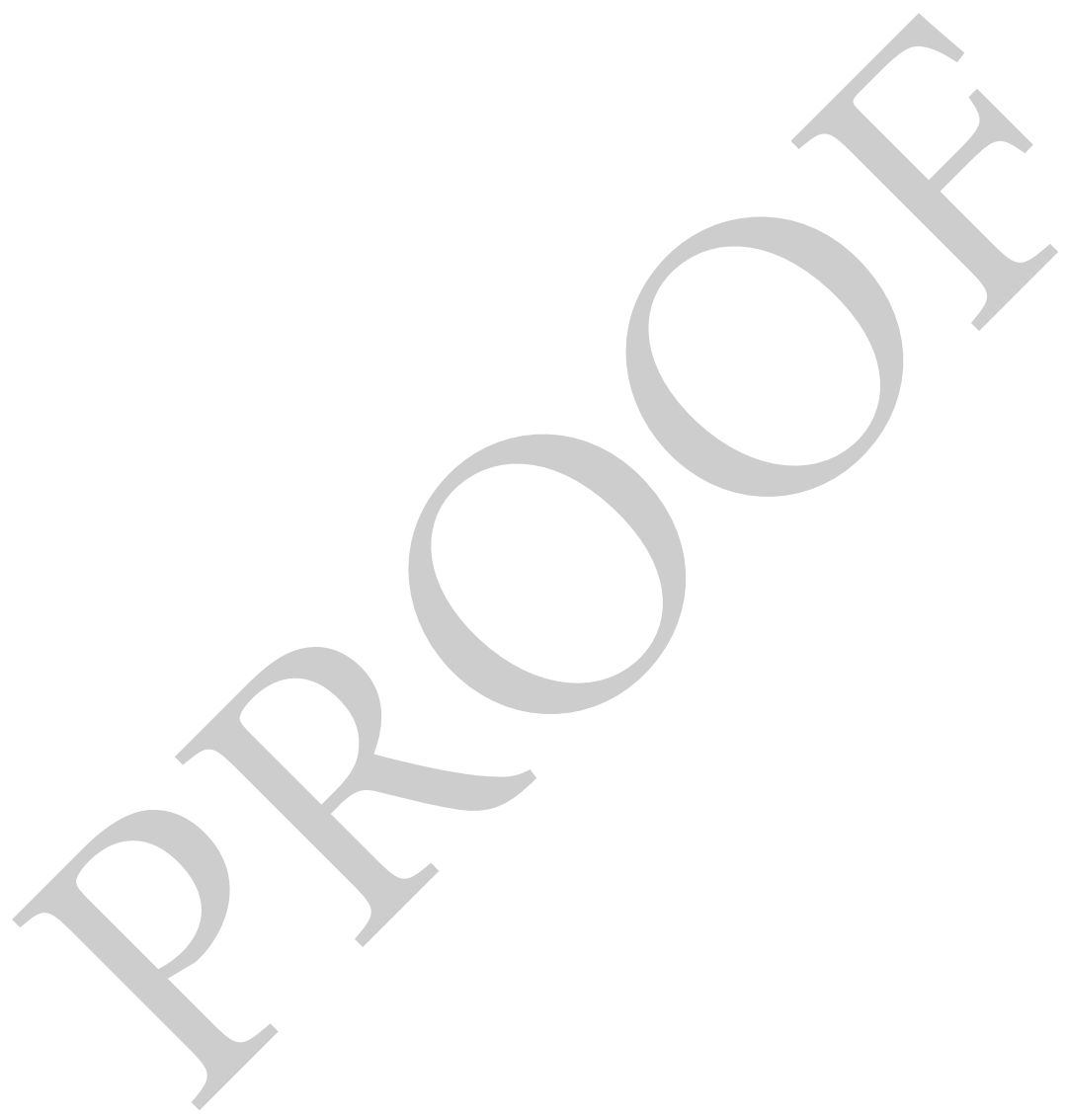

